ISSN: 2238-8052

\title{
NOVOS PARADIGMAS DE GOVERNANÇA: PROTAGONISMO DOS MOVIMENTOS SOCIAIS NO CONTRA-FLUXO DOS GRANDES PROJETOS URBANOS NA RMR
}

\author{
NEW PARADIGMS OF GOVERNANCE: PROTAGONISM OF SOCIAL MOVEMENTS IN THE CONTRA- \\ FLOW OF THE GREAT URBAN PROJECTS IN THE RMR
}

\author{
Riviane da Silva Monteiro LOPES ${ }^{1}$ \\ Suely Maria Ribeiro LEAL ${ }^{2}$ \\ Mônica Luize SARABIA ${ }^{3}$ \\ Felipe MORAES 4 \\ Wesley Morais da SILVA 5
}

Artigo recebido em 30/04/2019 e aceito em 09/07/2019

Palavras-chave:

Grandes Projetos Urbanos,

Movimentos Sociais,

Direito à cidade,

Governança,

Vila Naval.

\section{R E S U M O}

Neste artigo propõe-se analisar as formas de mobilização e participação popular organizadas pelos Movimentos Sociais Urbanos tendo em vista a promoção de conexões democráticas de luta e garantia pelo direito à cidade, de modo a se contraporem a apropriação do espaço metropolitano pelos Grandes Projetos Urbanos dentro do contexto recifense. Sendo assim faz-se importante o conhecimento dos processos de organização e participação no Planejamento e Gestão Democrática - Conferências, Conselhos, Assembleias etc.- que ordenam os conflitos entre as necessidades da população, a ineficiência do Poder Público e o Poder do Mercado Imobiliário. A inserção e até mesmo protagonismo desses atores sociais nos sistemas de Governança, antes dominados pelo Mercado Imobiliário e Poder Público, é resultado das práticas de resistência e luta pelo direito ao espaço urbano. Buscou-se aproximar o conhecimento teórico de um estudo de caso, sendo este o Movimento Resiste Santo Amaro que surge em contrapartida ao Grande Projeto Urbano da Vila Naval (Santo Amaro, Recife-PE).

\begin{abstract}
A B S T R A C T
In this article we propose to analyze the forms of mobilization and popular participation organized by the Urban Social Movements in order to promote democratic connections of struggle and guarantee for the right to the city, in order to counteract the appropriation of the metropolitan space by the Great Urban Projects within of the Recife context. Therefore, it is important to know the processes of organization and participation in Democratic Planning and Management - Conferences, Councils, Assemblies, etc. - that order conflicts between the needs of the population, the inefficiency of the Public Power and the Power of the Real Estate Market. The insertion and even protagonism of these social actors in the Governance systems, previously dominated by the Real Estate Market and Public Power, is the result of practices of
\end{abstract}

\footnotetext{
1 Graduanda em Arquitetura e Urbanismo na UFPE. Pesquisadora de Iniciação Científica do NUGEPP - Núcleo de Gestão Urbana e Políticas Públicas do MDU/UFPE. Bolsista PIC/FACEPE. E-mail: rivianelopes9787@gmail.com.

2 Professora Titular da UFPE - Universidade Federal de Pernambuco, Departamento de Arquitetura e Urbanismo. Coordenadora do NUGEPP - Núcleo de Gestão Urbana e Políticas Públicas do MDU/UFPE. Pesquisadora com Bolsa de Produtividade PQ/CNPq. E-mail: suelyleal@terra.com.br.

${ }^{3}$ Socióloga e Doutora em Desenvolvimento Urbano - Pesquisadora PNPD/CAPES e FACEPE, supervisora do NUGEPP - Núcleo de Gestão Urbana e Políticas Públicas do MDU/UFPE. E-mail: monicaluize@gmail.com.

4 Doutorando em Desenvolvimento Urbano na UFPE. E-mail: fmoraes@ymail.com.

${ }^{5}$ Graduando em Arquitetura e Urbanismo na UFPE. Pesquisadora de Iniciação Científica do NUGEPP - Núcleo de Gestão Urbana e Políticas Públicas do MDU/UFPE. Bolsista Pibic/CNPq - PROPESq. E-mail: wesleymorais98@gmail.com.
} 
resistance and struggle for the right to urban space. The theoretical knowledge of a case study was approached, being this the Resiste Santo Amaro Movement that appears in counterpart to the Great Urban Project of Vila Naval (Santo Amaro, Recife - PE).

\section{INTRODUÇÃo}

O atual modelo econômico - e urbano - surge após a crise do modo de regulamentação chamado Keynesianismo onde o Estado era o grande agente da economia e promotor do dito "bem estar social"; com a crise deste sistema o Mercado assume então o papel antes ocupado pelo Poder Público apostando em um sistema capitalista globalizado, mercado livre e forte ligação ao capital financeiro, assim como a estagnação do Estado Social. Nesse contexto as cidades são responsáveis por receber o excedente de capital, assumindo viés de mercadoria onde o próprio "Mercado" dita as regras. Nas cidades o tecido urbano está atrelado ao econômico sendo a apropriação do espaço pelos Grandes Projetos Urbanos um exemplo disso. A população inserida nesse cenário vivencia a cidade projetada pelas vontades do Mercado Imobiliário, a parcela que ousa projetar-se para além dessas circunstâncias o fazem pela garantia do direito à cidade, embora essa resistência se dê também na via do mercado informal.

0 direito à cidade está muito longe da liberdade individual de acesso a recursos urbanos: é o direito de mudar a nós mesmos pela mudança da cidade. Além disso, é um direito comum antes de individual já que esta transformação depende inevitavelmente do exercício de um poder coletivo de moldar o processo de urbanização (HARVEY, 2012 p. 74).

Tendo em vista as novas formas de articulação e participação popular em contrafluxo aos atuais processos de urbanização alavancados pelos Grandes Projetos Urbanos presentes na região metropolitana do Recife, justifica-se o estudo sobre essa atual dinâmica urbana onde o mercado imobiliário, representado pelos Grandes Empreendimentos Urbanos, impõe suas regras tomando o protagonismo, antes tido pelo Poder Público e favorecendo uma parcela da população em detrimento de outra, onde segundo De La Mora (1996, p.263):

A desigualdade política e a desigualdade fiscal faz com que, aqueles que, vítimas de desigualdades econômicas, em decorrência dos altos níveis de concentração de renda nacional, aqueles que mais necessitam de ação de Políticas Públicas para ter acesso subsidiado aos bens e serviços necessários à satisfação das suas necessidades e aspirações, encontrem-se em situação de exclusão (DE LA MORA, 1996, p.263).

Nesse sentido, o artigo busca entender os novos processos de organização popular que representam atualmente um importante ator na tomada de decisões acerca da cidade e sua urbanização, juntamente ao Poder Público e Mercado Imobiliário. A falta de inclusão da população com menor poder aquisitivo e pouca voz nas Políticas Públicas adotadas pelo Estado, Poder este que se submete às vontades do Mercado, através das parcerias Público-Privadas, onde segundo Harvey (1996, p.49) o Estado passa de gerenciador a empresário, tratando da cidade como mercadoria, a 
cidade com viés neoliberal, baseado no marketing urbano e nas competições intraurbanas. Em contraponto a essa prática, o objeto de estudo deste trabalho busca elucidar o processo de participação da sociedade no processo de implantação destas tipologias de empreendimentos, tendo a cidade do Recife como palco. É pela construção da cidade como espaço social, democrático e de participação popular que se legitima os anseios da população (LEAL, 2003).

Um urbanismo diferente do convencional surge com a articulação da população excluída (Movimentos de Resistência, Protesto, entre outros), o Urbanismo Subalterno é onde o oprimido, o "favelado" pode ser reconhecido, reivindicar e exercer pressão sobre outros atores tradicionalmente envolvidos nos arranjos de Governança, sendo ele mesmo então incluído como ator importante nesse sistema. Movimentos Sociais Urbanos como o "Ocupe Estelita" são exemplos desta articulação que constrói sua própria política de rua e reinventa o urbanismo, reivindicando seu direito à cidade. Segundo Ananya Roy (2017, p.10), “A política subalterna é, portanto, política popular e cultura popular".

Toma-se como estudo de caso, para levantamento de campo, o Movimento Resiste Santo Amaro que surge em contrapartida ao Grande Projeto Urbano da Vila Naval, Bairro de Santo Amaro. 0 campo torna-se pertinente a ser estudado tendo vista que o Resiste Santo Amaro é consequência da exclusão da ZEIS Santo Amaro em relação às decisões tomadas pelo Estado - representado pela Prefeitura da Cidade do Recife - e pelo Mercado acerca do terreno da Vila Naval, acordos da qual a comunidade não toma parte, sendo assim ela se organiza para reivindicar seu direito à cidade.

\section{APROXIMAÇõES TEÓRICO-METODOLÓGICAS}

O processo metodológico da pesquisa se deu inicialmente de forma exploratória por meio de um levantamento indireto bibliográfico e documental acerca dos Movimentos Sociais Urbanos e de Grandes Projetos Urbanos, utilizando-se de sites, textos, livros e artigos que serviram de base para a escolha e entendimento do objeto e seleção do Estudo de Caso. Assim como, foi realizado o levantamento da problemática acerca do tema, formulando perguntas com a pretensão de que as mesmas possam ser respondidas no desenvolvimento da pesquisa.

A apreensão do conteúdo literário se deu de forma crítica, procurando conectar o eixo teórico ao estudo empírico, a elaboração de fichamentos dos textos lidos facilitou o entendimento e proporcionou material para possível consulta, textos de autores como Harvey, Leal etc. foram imprescindíveis para a pesquisa. Após o levantamento teórico, se deu a construção do histórico do empreendimento da Vila Naval e dos Movimentos Sociais que surgem a partir disso, sobretudo o Resiste Santo Amaro (Estudo de caso), que serviram de amparo para a compreensão do Objeto de Estudo numa linha temporal onde se observou as demais propostas para a área, as organizações 
sociais que surgiram a partir de determinadas necessidades das comunidades. A averiguação do histórico serviu também para compreender a importância do objeto de estudo, os Movimentos Sociais Urbanos, em relação à história da cidade do Recife e suas mudanças ao longo do tempo.

Além do histórico, a caracterização geral do empreendimento e dos movimentos sociais esclareceu o impacto que um empreendimento desse porte tem como ele se configura, quem se beneficiaria com o projeto, quais atores estão direta ou indiretamente envolvidos, e o porquê dessa área ser tida como estratégica na cidade. A identificação dos arranjos de Governança, de Legislação da área de estudo, que compreende o Grande Projeto Urbano e o Movimento Social, foram de fundamental para o desenvolvimento da pesquisa.

Na etapa da pesquisa - categorizar empreendimento e construção do histórico - as informações foram obtidas por meio de pesquisa indireta através de internet, sobretudo as notícias acerca do empreendimento divulgadas em sites de notícias como o Diário de Pernambuco e o Jornal do Commercio, as informações mais específicas sobre o plano estão presentes no site da Prefeitura e na proposta elaborada pelo ICPS. Os detalhes sobre as movimentações sociais foram obtidas de artigos acadêmicos, do site dos direitos urbanos, do conselho da cidade do Recife e pelo perfil no facebook do Movimento Resiste Santo Amaro que atualmente é seu maior meio de comunicação e articulação.

A coleta de informações direta com os atores se deu inicialmente com entrevista entre André Torres representante do Movimento Resiste Santo Amaro e conselheiro tutelar, e Dona Vera também participante do movimento e representante do Fórum do PREZEIS na comunidade, sendo possível entender as reivindicações e percepções da comunidade acerca do projeto e como se dá a organização popular. Foram desenvolvidos questionários com a população da ZEIS como produto da última fase da pesquisa, questionários e entrevistas semiestruturadas, de início para a comunidade e posteriormente pretende-se aplicar com os demais atores, Poder público, Marinha e mercado imobiliário.

A pesquisa de campo ocorreu em Santo Amaro Norte, em abril de 2019, destinando-se a ZEIS Santo Amaro e a Vila Naval onde se buscou abordar informações diretamente dos moradores e usuários da área. Espera-se a aproximação com os Gestores, Prefeitura da cidade do Recife através do Instituto Pelópidas Silveira, e a Marinha, tendo em vista que o órgão federal é o atual proprietário do terreno da Vila Naval; tais sujeitos constam como próximos entrevistados e atores do Mercado tendo em vista responder novas indagações da pesquisa.

A aplicação do questionário para os moradores visou entender sua percepção do futuro Grande empreendimento que terão como vizinhos; aos gestores pretende-se captar como em sua visão o empreendimento é necessário e benéfico na área que virá a se instalar; dos participantes do Movimento Social Urbano é importante entender suas reivindicações e se o Grande Projeto Urbano da Vila Naval entra em acordo com seu entendimento de cidade democrática. A cada ator será destinado um questionário diferente, com o modelo de entrevista semiestruturada que possibilita captar a 
informações que se deseja, mas proporcionando liberdade ao entrevistado em suas respostas. Após a coleta destas entrevistas, os conhecimentos obtidos foram e serão armazenados em banco de dados e analisados visando auxiliar o desenvolvimento da pesquisa.

\section{A EMERGÊNCIA DE UM NOVO URBANISMO: A CIDADE NEOLIBERAL VERSUS A CIDADE DEMOCRÁTICA}

A partir da década de 1990, considerando as mudanças decorrentes do sistema capitalista globalizado, diversos autores como David Harvey e Milton Santos passam a fazer reflexões para compreender as contradições e os desdobramentos do processo de globalização, fortalecendo o debate, principalmente acerca da compreensão do espaço. Nesse sentido, Milton Santos define o espaço como:

[...] algo dinâmico e unitário, onde se reúnem materialidade e ação humana. 0 espaço seria o conjunto indissociável de sistemas de objetos, naturais ou fabricados, e de sistemas de ações, deliberadas ou não. A cada época, novos objetos e novas ações vêm juntar-se às outras, modificando o todo, tanto formal quanto substancialmente. (SANTOS, 2008, p. 46).

Harvey, por outro lado, parte do pressuposto de que para entender a sociedade atual e a sobrevivência do modo de produção capitalista é preciso atentar para as relações entre espaço e tempo. Assim, retoma a importância do conceito de espaço para as ciências humanas e sociais discutindo o ajuste espacial. 0 desenvolvimento desimpedido do capitalismo em novas regiões é uma necessidade absoluta para a sobrevivência do capitalismo. Essas novas regiões são os lugares onde o excesso de capitais super acumulados podem mais facilmente ser absorvidos, criando novos mercados e novas oportunidades de investimentos rentáveis (HARVEY, 2006, p. 118).

As formas de reprodução do capitalismo presentes na atualidade influenciam diretamente o modelo de cidade produzido no regime econômico designado fordismo. A cidade, até certo ponto seguia os preceitos estabelecidos por Henry Ford para a indústria, baseados na padronização e na racionalização do processo produtivo identificados, por exemplo, na arquitetura e urbanismo modernos do pós-guerra. O fordismo foi marco na ascensão do capitalismo, baseado na industrialização, na produção em massa dos produtos e consequentemente no aumento da capacidade de consumo da população, tendo em vista a superprodução que barateia os produtos mesmo que isso signifique perda de qualidade. Nesse contexto, o trabalhador industrial é indispensável, trabalhando por horas a fio em sistemas de trabalho rotinizados e padronizados, vê-se então a necessidade de organização desses trabalhadores, surgem então nesse momento os sindicatos de operários geralmente articulados a movimentos socialistas, comunistas e anárquicos - representavam grande força da mobilização popular assumindo a função de organizar e mobilizar os trabalhadores frente aos 
donos das fábricas, segundo Harvey (1992, p. 129): “0 acúmulo de trabalhadores em fábricas de larga escala sempre trazia, no entanto, a ameaça de uma organização trabalhista mais forte e do aumento do poder da classe trabalhadora, as corporações aceitaram a contragosto a organização sindical...”.

0 início da crise do fordismo se dá em meados da década de 1930, onde o excedente de produtos não é mais absorvido pelo mercado. Como forma de aumentar o mercado consumidor é implantado nos Estados Unidos o New Deal (1933-1937) tomando como base o sistema econômico elaborado pelo economista John Maynard Keynes - keynesianismo - o Estado investiu então em grandes obras de caráter público como usinas hidrelétricas, barragens, pontes, hospitais e etc., tal medida possibilitou a criação de empregos, diminuição das jornadas de trabalho com para a criação de novos postos e controle na produção tanto agrícola como industrial. No keynesianismo, implantado em diversos países, o Estado assume para si a responsabilidade de superação da crise e da economia, tomando medidas de protecionismo econômico - contra o liberalismo - e de pleno emprego, sendo assim o Estado torna-se o promotor do desenvolvimento econômico e social, garantido o conhecido estado de Bem-Estar Social - Welfare State. 0 fordismo junto as ideias keynesianas vivem sua "Era de ouro" entre as décadas de 1950 e 1960, o modelo fordista chega ao inevitável declínio na década de 1970 tendo em vista os estoques lotados e as pressões sindicais sofridas. Mais uma vez a figura do trabalhador industrial configura a parcela de mobilização popular, representados pelo ativismo sindical, tendo em vista o descontentamento dos trabalhadores com as condições trabalhistas nas fábricas e a discussão acerca dos problemas de classes que segue a lógica do explorador - donos das fábricas - e dos explorados - trabalhadores das fábricas.

Fazendo um paralelo com o New Deal e o Keynesianismo americanos com a realidade brasileira pode-se notar na Era Vargas (1930-1945) conceitos dessa tendência capitalista de supremacia Estatal, onde a proposição era a centralização do poder atribuindo ao Estado para o desenvolvimento econômico e social do país, onde o poder do capital privado era reduzido se comparado ao estatal. Outra característica identificada no governo Vargas, foi a relação com os sindicatos de trabalhadores industriais, para Getúlio a organização dos trabalhadores era vital para o governo, e incentivou esse tipo de mobilização popular com a criação de bases sindicais para garantir a unidade dos trabalhadores, já em Vargas, conforme discurso feito em $1^{\circ}$ de Maio de 1951:

Preciso de vós, trabalhadores do Brasil, meus amigos, meus companheiros de uma longa jornada; preciso de vós, tanto quanto precisais de mim. Preciso da vossa união; preciso que vos organizeis solidariamente em sindicatos; preciso que formeis um bloco forte e coeso que possa dispor de toda a força de que necessita para resolver os vossos próprios problemas. Preciso de vossa união para lutar contra os sabotadores para que eu não fique prisioneiro dos interesses dos especuladores e dos gananciosos, em prejuízo dos interesses do povo. Preciso do vosso apoio coletivo, estratificado e consolidado na organização dos sindicatos, para que meus propósitos não se esterilizem e a sinceridade com que me empenho em resolver os nossos problemas não seja colhida de surpresa e desarmada pela onda reacionária dos interesses egoístas, que, de todos os lados, tentam impedir a livre ação de meu governo. 
A crise do Fordismo e Keynesianismo dá-se principalmente pela rigidez dos sistemas, que não se adaptava a globalização e rapidez da circulação do capital, o sistema capitalista guiasse a partir de então por uma lógica de acumulação flexível, termo utilizado por Harvey (1992) para descrever a aplicação do capital em serviços e financeiros globais com a flexibilidade dos processos de trabalho, do mercado e dos produtos. A cidade necessita então se adaptar a nova ordem econômica, vivenciando esses processos capitalistas entre flexibilização do mercado, do Estado e as novas vivências sociais emergentes onde segundo Harvey (1989):

\begin{abstract}
As sucessivas revoluções tecnológicas, as relações de espaço, as relações sociais, os hábitos de consumo, os estilos de vida e similares, que caracterizam a história capitalista podem, como é sugerido por vezes, ser entendidos sem nenhuma indagação mais profunda sobre as raízes e a natureza dos processos urbanos...os capitalistas, como todo mundo, lutam no sentido de fazer sua própria geografia histórica (HARVEY, 1989, p. 49).
\end{abstract}

Esse modelo de acumulação de capital flexível está ligado a abertura do mercado, ao liberalismo e menor intervenção estatal, que culmina hoje no grande poder atribuído ao mercado e a fraca presença do Estado nos processos econômicos.

A cidade nesse contexto é então uma mercadoria, sendo alvo do mercado para receber parte do excedente do capital, a problemática então não é apenas econômica é antes de tudo urbana (HARVEY, 1996). As práticas neoliberais constroem então seu próprio modelo de espaço urbano, o empresariamento urbano é uma das características dessas cidades neoliberais, onde as parcerias público-privadas são voltadas, sobretudo para um caráter econômico excluindo os aspectos sociais desse cenário e tendo o capital privado como o agente mais poderoso desse sistema de governança e, o Poder Público passa de gestor a empresário da cidade apostando em práticas de marketing e de planejamento estratégico (COMPANS, 2005; HARVEY, 1996).

Tendências de "embelezamento" das metrópoles surgem como forma de inserir a cidade nas competições interurbanas, os Grandes Projetos Urbanos são um exemplo disso, projetos pontuais de grande escala viabilizados pelo mercado imobiliário e Poder Público local em parceria (HARVEY,1 996), projetos esses que atendem as parcelas de população com maior poder aquisitivo e se instalam em territórios estratégicos - seja em relação a ambiências naturais como RioMar etc, ou em relação a boas infraestruturas muitas vezes cedidas pelo Estado. 0 investimento do Poder Público nesses Grandes Projetos Urbanos significa por vezes a falta de atenção a problemas mais urgentes na cidade e que impactam uma maior região e população "a hegemonia política neoliberal resultou na redução dos gastos sociais, afetando o financiamento público para a construção habitacional e para a infraestrutura urbana" (COMPANS, 2005), e segundo Harvey (1996, p.63):

Deveria reconhecer também que, atrás da máscara de muitos projetos bem-sucedidos, se encontram sérios problemas sociais e econômicos, os quais em muitas cidades, estão assumindo a forma geográfica de uma cidade dual: de um centro renovado cercado por um mar de pobreza crescente. 
Nesse contexto os movimentos sociais assumem então um caráter urbano - não mais sindical e trabalhista - visto que a luta agora é pelo direito à cidade, a mobilização popular se contrapõe a apropriação do espaço urbano pelas práticas neoliberais como os Grandes Projetos Urbanos.

A atribuição de poder aos governos locais possibilitou tanto a construção da cidade neoliberal como a do ideário da cidade progressista e democrática, o modelo centralizado do poder estatal foi de grande importância no momento pós-guerra e nos modelos econômicos expansionistas com um governo nacional forte e provedor - Era Vargas, New Deal etc. -, a decadência desse sistema dá-se, sobretudo a crise de governabilidade, da crescente ineficiência econômica Estatal e do esgotamento do modelo do Estado produtor frente às tendências internacionais de globalização econômica (HARVEY, 1992).

A constituição de 1988 vem para reafirmar a democracia política e social após a excessiva centralização da ditadura militar de 1964, prevendo instrumentos de prática democrática como os Conselhos, Planos Diretores, Orçamentos Participativos e outras formas de inclusão popular e descentralização de poder para os municípios (LEAL, 2003). Os municípios estariam mais próximos das demandas populares, sendo assim seriam mais eficientes em atendê-las, afirmando os governos locais enquanto importantes agentes de democratização do Estado. Nesse momento as mobilizações populares estão voltadas, sobretudo para as demandas da sociedade local e a interlocução entre esses agentes sociais - lideranças populares, ONG's, membros da Igreja e etc. - e o poder público municipal. 0 protagonismo dos governos locais delega à municipalidade questões econômicas e financeiras antes de responsabilidade do Estado Nacional, levando as cidades à competição interurbana tendo em vista receber mais investimentos econômicos federais e do mercado privado incorporando o empreendedorismo e marketing urbano as gestões, inserindo as cidades não só em competições entre si assim como em cenário globalizado internacional. A cidade democrática é representada pela participação popular nas gestões locais, com a utilização de instrumentos como o Plano Diretor que prevê formas de inclusão popular em escala municipal onde:

\footnotetext{
A legitimação política da democracia participativa criaria espaço para a construção de uma "nova hegemonia", onde seria "possibilitado" aos setores populares assegurar um lugar nas decisões estratégicas e no controle social das ações do governo municipal (LEAL, 2003, p. 79).
}

A cidade neoliberal por sua vez caracteriza-se pela elaboração de um plano estratégico voltado para o caráter econômico e empresarial urbano, descrito por Leal (2003, p. 78) como: "O crescimento da tendência do empreendedorismo local teria relação com o poder de ação dos diversos atores envolvidos, particularmente dos agentes econômicos e das regras ditadas pelos mercados globais".

O que se observa atualmente nas dinâmicas urbanas e econômicas é o conflito entre esses dois paradigmas de cidade, o avanço constante do Mercado na apropriação do espaço urbano e a luta dos 
atores sociais pela construção desse espaço de forma democrática, onde geralmente a vontade do capital privado é quem dita as regras:

A consequência direta desse processo de hegemonia dos agentes econômicos é a fragmentação do planejamento democrático, demonstrado pela fragilidade da estrutura político-institucional estatal e pelo desequilíbrio de poder entre os agentes sociais na disputa pela apropriação do espaço, o que evidencia uma governança urbana inversa na regulação do espaço (LEAL, 2014, p.175).

A valorização excessiva dos aspectos econômicos em detrimento dos aspectos sociais, culturais e históricos é um padrão que se repete mundialmente, as cidades que recebem o status de cidades desenvolvidas geralmente o ganham tendo em vista seu avançado desenvolvimento econômico. Essa visão economicista do mundo coloca os países de primeiro mundo - os antigos colonizadores, e dominadores de antigos impérios - "praticamente toda a infraestrutura, e também o capital e a capacidade de aumentá-lo, já estavam presentes na capital imperial no início do século XX, muito antes de ser renomeada como cidade global" (KING, 2010, p.4).

0 acirramento da disputa econômica entre cidades - seja pelo status de cidade mundial, seja uma disputa interurbana - leva ao agravamento de questões como a segregação sócio-espacial, delimitando mais ainda a barreira já existente entre ricos e pobres, esse fenômeno é observado tanto na escala da cidade como em escala global (KING, 2010). Nesse sentido, fica claro que apenas aspectos econômicos e padrões eurocêntricos não são suficientes para descrever e contornar os problemas em países/cidades de terceiro mundo é necessário então uma nova abordagem dos processos urbanos e econômicos existentes, uma visão contra hegemônica, descolonial, levando conhecimento do Sul para o Norte hegemônico, colocando no centro das discussões o subalterno. A partir dessa teoria póscolonial, nota-se o desenvolvimento de um novo urbanismo, o Urbanismo Subalterno definido por Ananya (2010, p.10) como:

O urbanismo subalterno é então um paradigma importante, pois busca conferir reconhecimento a espaços de pobreza e formas de agência popular que muitas vezes permanecem invisíveis e negligenciadas nos arquivos e anais da teoria urbana...a subalternidade passou a ser vista como a condição do povo, daqueles que não pertenciam e não podiam pertencer às classes de elite... A política subalterna é, portanto, política popular e cultura popular.

Nesse sentido, a emergência da força popular através dos movimentos sociais urbanos, têm um viés descolonial e contra hegemônico, fazendo frente aos modelos globalizados e elitizados representados pelos Mega Projetos Urbanos. Assim como propõe a teoria pós-colonial - uma análise do Sul global para o Norte, contrariando os padrões adotados e colocando em pauta o que o Norte precisa aprender do Sul - faz-se necessário uma interpretação dos atuais conflitos urbanos entre Mercado, Poder Público e os movimentos sociais, observando o que as organizações populares impõem ou modificam nos "pacotes" padronizados que são os Grandes Projetos - o que o Movimento Resiste Santo Amaro representa na implantação do Projeto para a Vila Naval. Definido por Nick-Peck-Brenner (2009) como hibridismo dos pacotes neoliberais - Master Projects - é a capacidade desses projetos de 
se adaptarem a uma realidade existente de aspectos culturais ou pressões sociais exercidas, tendo em vista o aumento da sua capacidade de sucesso na implantação dos projetos.

A neoliberalização é baseada no desenvolvimento espacial desigual e se materializa através dessa desigualdade... a evolução concomitante de agendas neoliberais relacionadas a políticas estatais e suas estratégias de reestruturação em sua interação conflitante com as condições e disposições políticas econômicas, regulamentares e 'geometria do poder' contextualmente específico... isso levanta a clara possibilidade de que a família de híbridos do neoliberalismo que são significativos tanto analítica quanto politicamente, possa não apenas ser povoada de 'variedades' ou 'modelos' nacionais de neoliberalismo, mas também pode incluir uma série de formações e conjunturas urbanas características (NICK-PECK-BRENNER, 2009, p.8).

A emergência do Movimento Resiste Santo Amaro, representa a luta pela construção de cidade democrática, frente à cidade projetada pelo Mercado, demonstrando a força das práticas de resistência e luta pelo direito à cidade.

\section{CARACTERIZANDO O EMPREENDIMENTO E O MOVIMENTO SOCIAL URBANO}

A área onde se localiza a Vila Naval no bairro de Santo Amaro, terreno pertencente à Marinha, possui histórico de diversas propostas e planos de urbanização por se tratar de uma área margeada pelo Rio Beberibe, caracterizada como sendo de dinamização econômica, que faz parte do Centro Expandido do Recife, assim como é fronteiriça a cidade de Olinda, ficando evidente o interesse do Poder Público em valorizar essa área estrategicamente visando atrair o Mercado (Figuras 1 e 2).

Figura 1. Primeira versão do Grande Projeto Urbano Santo Amaro Norte, 2014.

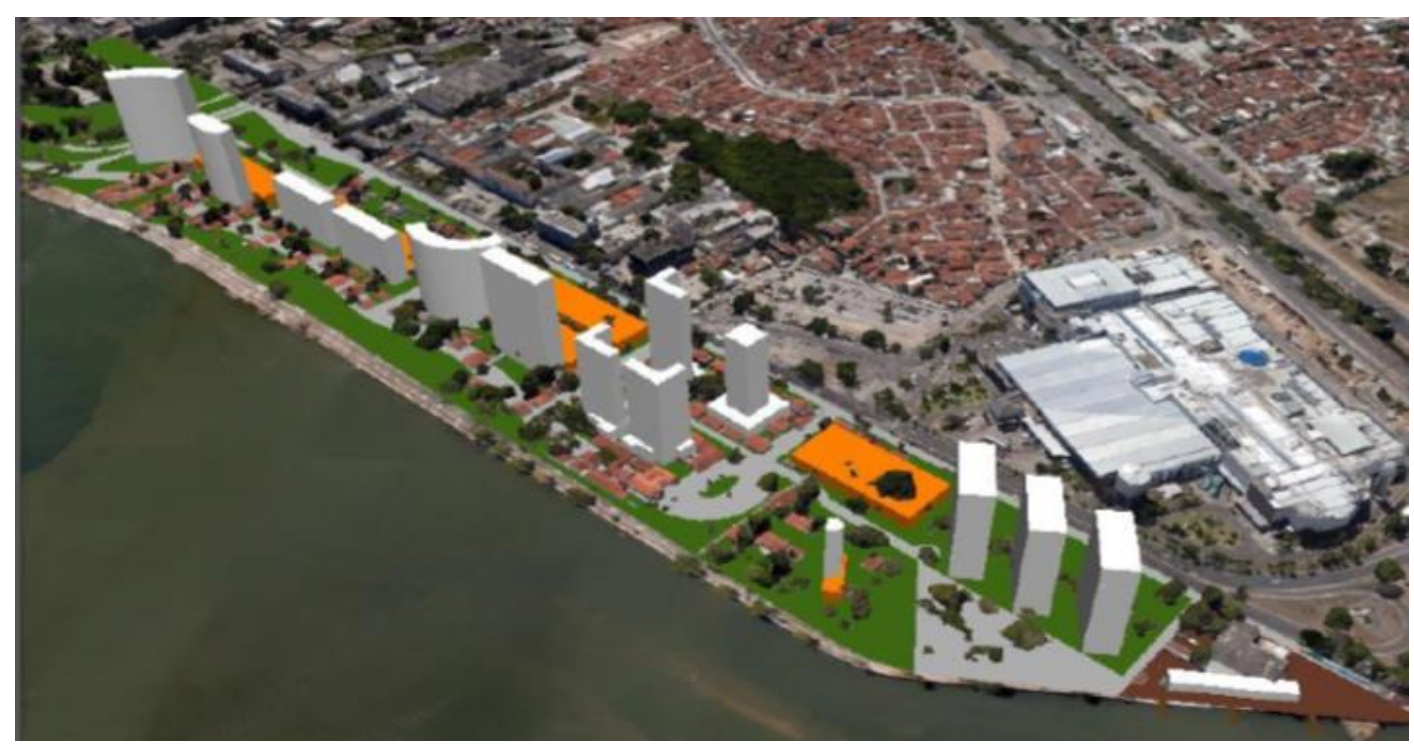

Fonte: Site Direitos Urbanos, 2015. 
Figura 2. Segunda versão Projeto Santo Amaro Norte, 2017.

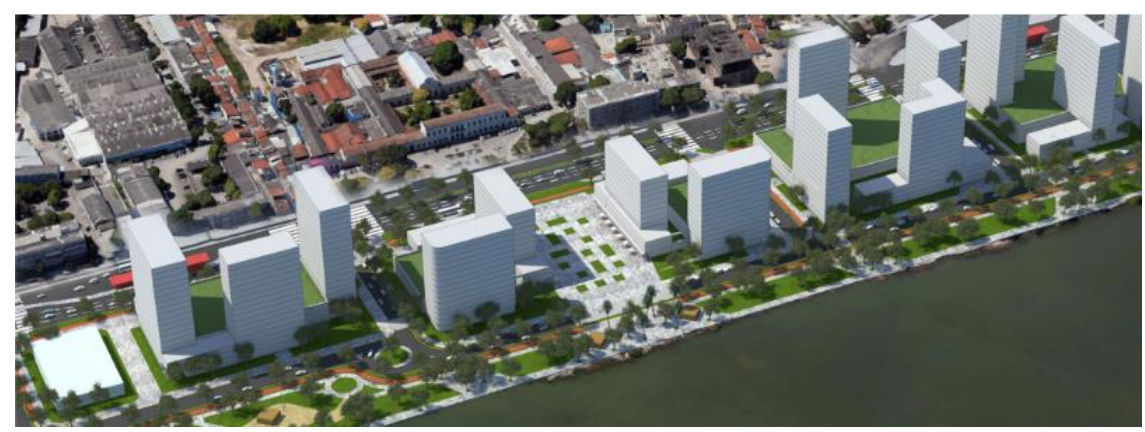

Fonte: Plano Santo Amaro Norte, versão para discussão, 2017.

Os resultados históricos dessa dinamização urbana em uma área estratégica como a Vila Naval trazem a tona questionamentos de como deve se dar sua renovação e a quem ela visa atender, tendo em vista que tal processo repercute de forma significativa não só em seu entorno imediato, mas na cidade, na paisagem e no patrimônio existente. Santo Amaro outrora, local que abrigava os mocambos recifenses, bairro estigmatizado pela violência e formado por grandes comunidades como as ZEIS (Zona Especial de Interesse Social) Santo Amaro e João de Barros, hoje é considerado área de desenvolvimento econômico, recebendo empreendimentos como grandes empresas de telecomunicação assim como igrejas e hospitais de porte interestadual, o quadrilátero de Santo Amaro (lugar entre a Av. Cruz Cabugá, Mario Melo, Av. Norte e Rua da Aurora), Shopping Tacaruna e Grandes Projetos Propostos para a Vila Naval (Figura 3).

Figura 3. Localização do bairro de Santo Amaro, da Vila Naval e dos eixos viários, respectivamente.

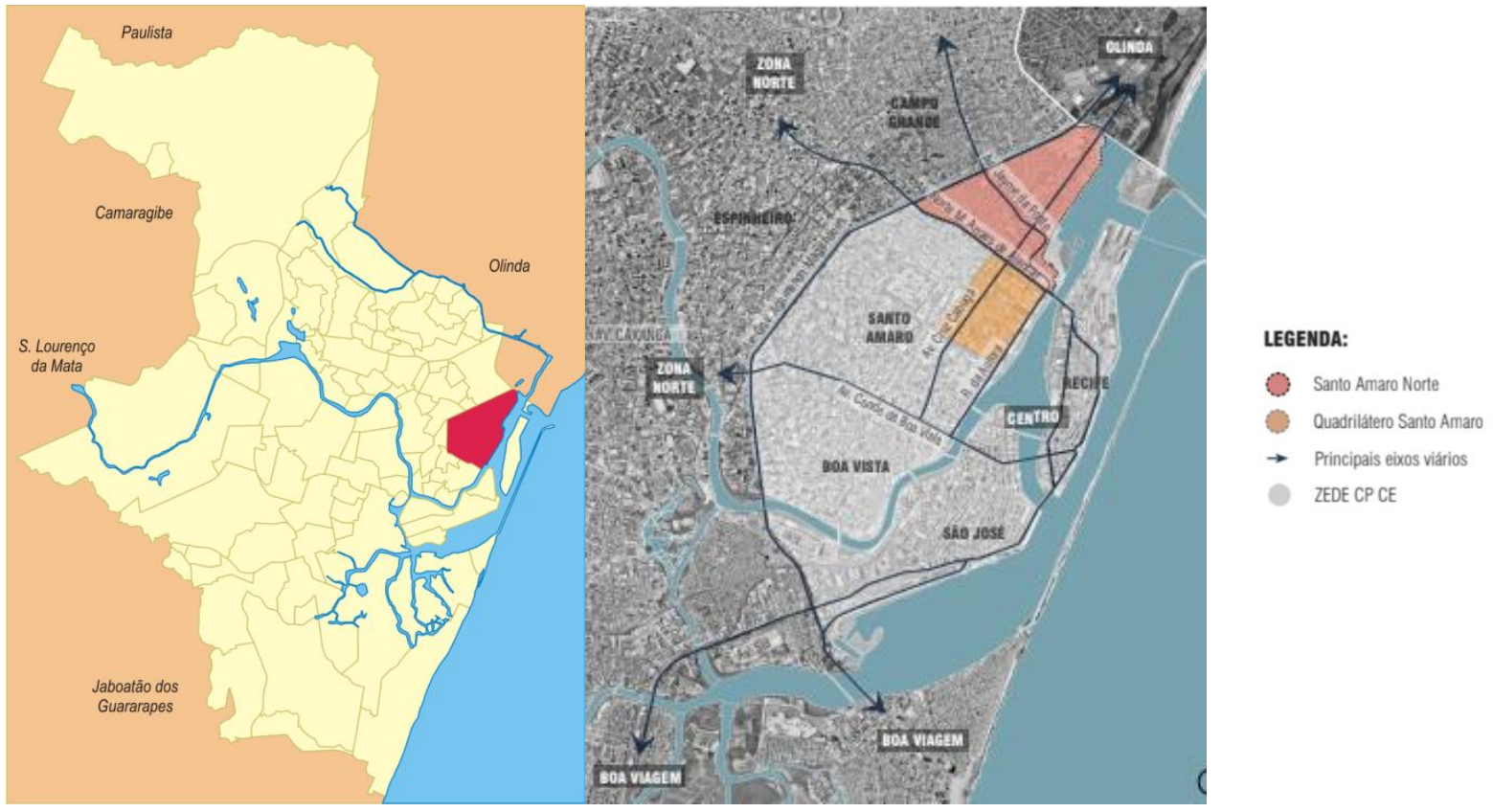

Fonte: Prefeitura do Recife; Plano Santo Amaro Norte, versão para discussão. 
Sendo uma das primeiras propostas a abarcar a área o Projeto Recife-Olinda (2006), a proposta urbanística visava transformar a faixa litorânea entre as duas cidades, área tida como degradada passaria por requalificação urbana fortalecendo a rede cultural e turística da região. Segundo Raquel Rolnik “Um dos pontos fortes é a inclusão social e territorial das populações carentes”, comunidades de baixa renda como Santo Amaro, Pilar e Coque passariam por renovação urbana, entretanto o projeto não saiu do papel.

O Plano Diretor do Recife de 2008 determina áreas passíveis de receber projeto especial, haja vista seu potencial paisagístico, cultural e econômico, estando a área correspondente a ZEIS Santo Amaro/Tacaruna/Vila Naval incluída nesses parâmetros. Após anos do projeto Recife-Olinda, surge o plano de 2014, o Plano Específico para a Zona Especial de Preservação do Patrimônio Histórico e Cultural - ZEPH 19 - Hospital de Santo Amaro/Vila Naval, projeto de Lei apresentado pela Prefeitura do Recife através do Instituto das Cidades Pelópidas Silveira. 0 plano tinha em vista trazer renovação urbana, tendo princípios como valorizar a visada do Hospital de Santo Amaro - Edificação histórica datada de 1870 -, implantar parque linear na frente d'água, o aumento do gabarito da área de até 25 pavimentos, com diversidade de uso com finalidade de revitalizar a área e o alargamento da Cruz Cabugá. Sendo assim nota-se que o Plano não estava em acordo com os atuais parâmetros urbanísticos previstos para a área, ferindo o caráter de preservação histórica do Hospital e seu entorno.

Descontentes com o plano apresentado, a sociedade civil passou a se organizar, por meio do grupo Resiste Santo Amaro para fazer suas reivindicações ao Poder Público, e em busca de discutir a reurbanização do bairro e o projeto proposto. 0 movimento foi formado por moradores do bairro, lideranças da comunidade como André Torres, conselheiro tutelar da área, e dona Vera, representante do PREZEIS na comunidade, vereadores como Luiz Eustáquio (na época filiado ao PT), Felipe Cury assessor da ALEPE, e o grupo direitos urbanos representado por Leonardo Cisneiros (conhecido pelo envolvimento no caso do Ocupe Estelita) (Figura 4).

Figura 4. Integrantes do Movimento Resiste Santo Amaro.

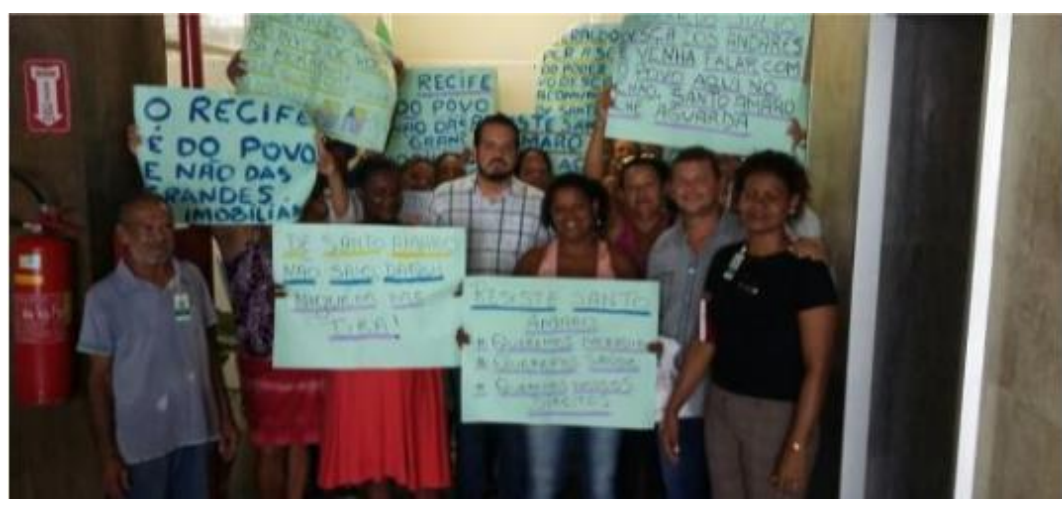

Fonte: Folha PE, junho de 2015. 
Primeiramente o grupo pediu a devida participação da comunidade em audiências públicas, sendo as audiências públicas um dos mecanismos importantes na construção do diálogo da população com o Poder Público, a fim de construir políticas públicas democráticas (Leal, 2003). Assim como também questionava o plano acerca da preservação do patrimônio existente, haja vista que o atual padrão de ocupação da área era de Vilas de meados da década de 1950, com gabaritos de 2 pavimentos.

Segundo o movimento o plano do Vila Naval feria também o patrimônio histórico que é o Hospital de Santo Amaro. Para, além disso, o encerramento das atividades da Escola Almirante pelo Poder Público em 2015, localizada no terreno da Vila, mas utilizada pela população da ZEIS Santo Amaro há mais de 40 anos, soma com mais um dos descontentamentos da comunidade com relação à proposta. A falta de inclusão da população nas negociações e tomada de decisões também foi um ponto abordado pelo Movimento, que afirmava que as negociações a respeito do plano deram-se entre Prefeitura e Marinha, e com o Mercado representado pela ADEMI-PE (Associação de Empresas do Mercado Imobiliário de Pernambuco).

A área da ZEIS Santo Amaro não entrava na proposta de intervenção do Projeto, o que implicou um desacordo com o Plano Diretor de Recife do ano de 2008, que previa plano especial para a área da ZEIS Santo Amaro/Tacaruna/Vila Naval. Com a proposta do alargamento da Cruz Cabugá em 4 faixas ficava claro a priorização do carro, tornando uma ambiente hostil para o pedestre e separando ainda mais a ZEIS do terreno da vila - cessando a relação existente entre a comunidade e a Vila e até mesmo com o próprio Rio Beberibe - , o medo da especulação imobiliária também era uma das aflições da comunidade tendo em vista que a demasiada valorização econômica da área poderia causar "expulsão branca" dos moradores.

Essas e outras reivindicações do Movimento Resiste Santo Amaro, foram feitas por meio de audiência pública em 2015, via blog dos Direitos Urbanos e pela página de facebook do Movimento (sendo a internet a mais utilizada forma de mobilização popular contemporânea, observada em casos como o Ocupe Wall Street, Ocupe Estelita etc.), chegando a realização de protesto na Prefeitura do Recife também em 2015. O Plano Urbanístico apresentado em 2014 foi remodelado devido à rejeição da população, e assim foi reapresentado em 2017 com alterações e com o nome de Plano de Santo Amaro Norte.

O Plano Santo Amaro Norte é de responsabilidade do Instituto das Cidades Pelópidas Silveira e tem como objetivo integrar o terreno a malha urbana existente, promover o aumento de densidade populacional, priorizar o pedestre, ciclista e transporte público (qualificando o funcionamento do BRT na Cruz Cabugá), incrementar espaços públicos, implantar diversidade de usos, proteger o patrimônio existente, gerar emprego para a população da ZEIS, assim como direcionar todas as ações mitigadoras do empreendimento a ZEIS. 0 plano específico de 2014 foi englobado ao de 2017 visto que esse é mais 
amplo e abarca uma maior área de intervenção e possui propostas mais efetivas. 0 gabarito máximo definido é agora de 21 pavimentos, a proposta do parque linear e maior quantidade de espaço públicos também é apresentada. Neste plano urbanístico a ZEIS é finalmente incluída, porém são traçadas apenas diretrizes projetuais, até certo ponto genéricas, e sem a escuta da população, que atualmente em sua grande maioria não conhece o projeto.

0 alargamento da Av. Cabugá continua como parte da concepção do projeto, assim como a construção de estação fluvial, e implantação de praça defronte ao Hospital de Santo Amaro como forma de amenização da visada para o patrimônio. Como diretriz para ZEIS o ICPS aponta a possibilidade de alargamento de algumas ruas e demolição de assentamentos considerados insalubres e que atrapalhem a mobilidade do local, propondo a realocação dessa população para unidades multifamiliares.

Antes mesmo da apresentação efetiva em audiência pública do Plano Santo Amaro Norte em 2017, os movimentos sociais se mobilizaram mais uma vez, não contra o plano, mas exigindo sua participação no processo de elaboração e atendimento das demandas da comunidade no projeto. Representantes do Movimento Resiste Santo Amaro, do Conselho da Cidade do Recife, dos Direitos Urbanos, do Mestrado em desenvolvimento urbano da UFPE e do Plano Centro Cidadão da UNICAP entram em contato do Ministério Público de Pernambuco - MPPE, tendo em vista o debate acerca validade do projeto. Em 2015 o MPPE que já estava envolvido nas negociações acerca do terreno da Vila Naval, ajuizou ação civil pública para compelir o Município do Recife a encaminhar a votação na Câmara dos Vereadores o projeto de Lei anteriormente intitulado Plano Específico para a Zona Especial de Preservação do Patrimônio Histórico e Cultural - ZEPH 19 (Hospital de Santo Amaro e Vila Naval). Após investigação, o MPPE decide por pedir a suspensão do Plano (que até hoje se encontra suspenso e não saiu do papel), questionando sua nulidade visto que não houve participação popular, e as oficinas desenvolvidas pelo Plano Centro Cidadão alegadas pelo ICPS como forma de ouvir a comunidade não foram direcionadas ao estudo da Vila Naval e sim do bairro de Santo Amaro como um todo, fazendo-se necessário então novos estudos nas comunidades sobre as necessidades da área.

O Ministério Público exige também a elaboração de um Estudo de Impacto de Vizinhança e um Estudo prévio de Impacto Ambiental. 0 coletivo do Direitos Urbanos alega que a barganha feita entre o Poder Público, o ICPS e a comunidade se baseia em chantagens onde os elaboradores do plano citam a necessidade do projeto ser viável economicamente com empreendimentos que possam vir a dar rápido retorno financeiro levando a Marinha a aceitar a proposta, só assim o projeto da ZEIS se faria viável e iria além da proposta de diretrizes, ou seja a comunidade só ganha depois que o mercado levar sua grande parcela do negócio.

A forma de elaboração do plano por parte da prefeitura leva a comunidade a ter que concordar com todas as propostas de um empreendimento privado que o viabilizam como a destruição da 
ambiência dos setores de preservação histórica e ambiental, para que assim possam ganhar algum benefício.

\section{O MOVIMENTO RESISTE SANTO AMARO EM CONTRAPONTO À VILA NAVAL}

As práticas neoliberais globalizadas são observadas no Mercado Imobiliário recifense e na apropriação do espaço urbanos por esses modelos de Master Projects, projetos muitas vezes viabilizados por grandes investimentos públicos e privados, e a financeirização dos sistemas de capitalização, a instalação desses projetos no território metropolitano dão-se por uma tendência de empreendedorismo urbano, onde a capital é inserida em um modelo de "embelezamento urbano" (HARVEY, 1996).

O Grande Projeto Urbano proposto para a Vila Naval não é uma prática isolada, é um paradigma que se repete na cidade do Recife, um plano estratégico com a instalação de grandes empreendimentos de caráter elitizados e/ou turísticos, especialmente nas áreas de centro histórico e próximos a amenidades naturais como rio ou mar, podendo-se apontar o Porto Digital, Shopping RioMar, Porto Novo Recife e o conhecido caso do Projeto Novo Recife no Cais José Estelita. É importante destacar este último caso devido a relevância das relações e conflitos estabelecidos entre Mercado, Poder Público e sociedade civil, de responsabilidade do Consórcio Novo Recife o projeto vai de encontro aos modelos de cidade mercado, desprezando entorno imediato, patrimônio histórico, paisagem e até mesmo legislação. Assim sendo, há uma grande comoção da sociedade civil, de forma que o Movimento Social Urbano Ocupe Estelita fica conhecido internacionalmente por seus atos e protestos.

Seguindo esse plano estratégico iniciado no centro do Recife, esses parâmetros chegam agora ao Centro Expandido da cidade, Santo Amaro - Vila Naval, e mais uma vez os atores sociais se mobilizam como forma de refrear as ações dessa governança corporativa. Apontados por alguns como o "Novo Estelita", o caso da Vila Naval representa mais uma vez a crise de governabilidade local, devido à inibição do Estado frente aos poderes do Mercado e as necessidades da sociedade civil (LEAL,2014).

Por meio da aproximação com a comunidade de Santo Amaro, estabelecida com a aplicação de questionários para atender as demandas da pesquisa, percebeu-se que a população da ZEIS Santo Amaro como um todo, não tem conhecimento a respeito do projeto proposto e muito menos a respeito das medidas que serão tomadas no Plano de Santo Amaro Norte em relação à própria ZEIS. Ou seja, apesar dos representantes da comunidade que participam ativamente do movimento Resiste Santo Amaro, nota-se a falta de diálogo entre essas lideranças e a comunidade, visto que não há uma participação efetiva e nem uma tentativa de diálogo entre as partes envolvidas. Confirma-se que não é 
estabelecida uma Gestão Democrática e inclusiva por parte do poder público ficando evidente a necessidade de implementação de instrumentos como Assembleias Públicas, Conselhos, Oficinas, Palestras e mais espaços de escutas da população.

Vale ressaltar que, grande parte dos moradores tem vínculo com o terreno da Vila Naval devido à ocupação de cerca de 30 ou 40 anos atrás, fazendo parte da história de vida desses moradores na qual o espaço em discussão, era dotado de escola, quadra de esportes e auxiliava na pesca dos moradores, e que a completa remodelação deste espaço pelo projeto altera essa vivência social estabelecida.

Os líderes comunitários que participam da mobilização social da comunidade são figuras pontuais e que já possuem conhecimento a respeito das práticas democráticas, como exemplo tem-se Dona Vera, representante reconhecida pela comunidade e que atua no PREZEIS, e André Moraes, conselheiro tutelar que age no que tange às audiências públicas e ao repasse de informações por meio das mídias digitais. Ou seja, apesar do número pequeno de pessoas envolvidas na linha de frente do Movimento, os representantes procuram mobilizar toda a comunidade, levando conhecimento a respeito do Plano através de reuniões no bairro e abrindo espaço de escuta.

Mesmo que os moldes capitalistas dos Grandes Projetos Urbanos sejam inibidores de mobilização social, o Resiste Santo Amaro surge como forma de questionar os modelos do projeto proposto e representa uma forma de resistência e remodelação dos sistemas de governança, inserindo a população no espaço antes dominado pela governança corporativa. Um dos ganhos do movimento foram as alterações realizadas no plano original, acatando algumas das exigências da população, constatando o hibridismo do projeto, conforme destaca Nick-Peck-Brenner (2009), e o embargo desse mega empreendimento, apontando a possibilidade da total reestruturação do projeto urbano/arquitetônico tendo em vista as pressões sociais exercidas ao longo desses anos.

\section{CONSIDERAÇÕES FINAIS}

A partir das formas de análise realizadas percebe-se a importância que os Movimentos Sociais Urbanos possuem na construção de uma cidade inclusiva, dando voz e espaço de representação a atores sociais excluídos por um sistema urbano globalizado capitalista com caráter neoliberal, onde o Estado se submete cada vez mais ao Mercado, favorecendo-o, por exemplo, com isenção de impostos, concessão de favores e etc., e negligenciando a população mais necessitada.

As ocupações espontâneas dos mais pobres, assentamentos de baixa renda em condições de precariedade, é o que resta de cidade aos excluídos das Políticas Públicas, segundo Leal "As desigualdades e a marginalidade urbana, os enormes déficits de infraestrutura e serviços públicos, a fragilidade do próprio tecido social, certamente são inibidores da capacidade de nossas cidades 
exerceram essa função de agente político promotor do desenvolvimento e da democracia." (2003, p. 59). As comunidades que ousam desafiar o sistema hegemônico o fazem por necessidades básicas como direito à moradia, melhores infraestruturas e maior qualidade de vida. Sendo assim instrumentos de inclusão da população e o fortalecimento das organizações populares como o Orçamento Participativo, a Assembleia dos Moradores e dos Bairros, e as Audiências Públicas são fundamentais para a construção de uma gestão democrática, inclusiva e voltada para uma maioria geralmente excluída.

A disputa dos atores sociais pelo direito à cidade questiona a apropriação do espaço pelas classes capitalistas, nesse sentido no Movimento Resiste Santo Amaro as práticas de mobilização popular surgem em busca de conexões democráticas e garantia de poder decisão sobre o espaço urbano que os rodeia, se contrapondo a apropriação do espaço metropolitano pelo Grande Projeto Urbano. A luta pela cidade desse movimento, é a luta também contra a especulação imobiliária que rechaça populações de assentamentos consolidados e de baixa renda; Santo Amaro atualmente passa por rápido desenvolvimento econômico, atraindo as classes mais altas para o local e o terreno da Vila Naval com grande espaço territorial, margeado pelo rio Beberibe e por vias importantes, é um forte alvo dessa especulação.

0 direito coletivo à cidade implica na utilização social do espaço, apropriação pelo corpo, transformando o espaço público em comuns políticos (HARVEY, 2014). 0 processo de urbanização se dá de forma acelerada e capitalista, gerando um espaço urbano elitizado e excludente, sendo as formas de ingresso dos excluídos nesse espaço os canais de lutas, a insurgência do Urbanismo Subalterno dotando o subalterno de caráter político e por meio dos Movimentos Sociais Urbanos.

Nessa perspectiva, o subalterno e a organização popular ganham força ao ponto de modificar os projetos arquitetônicos/urbanos neoliberais, levando esses "pacotes" globalizados a se modificarem/hibridizarem, demonstrando assim o poder ganho por esses atores sociais através de práticas de resistências, chegando a moldar partes da cidade.

\section{REFERÊNCIAS}

BRENNER, Neil; PECK, Jamie; THEODORE, Nik. Urbanismo neoliberal: La ciudad y el imperio de los mercados. Temas sociales $\mathrm{n}^{\circ} 66$, março de 2009.

CISNEIROS, Leonardo. Relato de audiência sobre a Vila Naval. Direitos Urbanos Recife. Publicado em novembro de 2014. Disponível em: <https://direitosurbanos.wordpress.com/2014/1 1/20/relato-da-audiencia-sobre-a-vila-naval/>. CISNEIROS, Leonardo. Um plano, duas chantagens. Direitos Urbanos Recife. Publicado em setembro de 2017. Disponível em:
$<$ https://direitosurbanos.wordpress.com/2017/0 9/23/um-plano-duas-chantagens/>.

COMPANS, Rose. Empreendedorismo Urbano: entre o discurso e a prática. São Paulo, Editora UNESP, 2005.

DE LA MORA, Luis. A aferição e o aperfeiçoamento da eficiência no exercício dos papéis dos novos atores sociais na gestão descentralizada das políticas públicas. Organizado por Norma Lacerda de Melo e Suely Leal. Relação Público-Privado: do Local ao Global. Recife, 1996, p. 261-286. 
DILGER, Gerhard; LANG, Miriam; FILHO, Jorge Pereira (Organização). Descolonizar o Imaginário: debates sobre pós-extrativismo e alternativas ao desenvolvimento. Editora Elefante. Disponível em: $<$ https://rosaluxspba.org/wpcontent/uploads/2016/08/Descolonizar_o_Imagi nario_web.pdf>.

HARVEY, David. Cidades Rebeldes, do direito à cidade à revolução urbana. São Paulo, Editora Martins Fontes, 2014.

HARVEY, David; MARICATO, Ermínia; DAVIS, Mike; [et al.]. Cidades Rebeldes: Passe Livre e as manifestações que tomaram as ruas no Brasil. São Paulo, Editora Boitempo, 2013.

HARVEY, David. A produção capitalista do espaço. $2^{\mathrm{a}}$ edição. São Paulo: Annablume, 2006.

HARVEY, David. Do gerenciamento ao empresariamento: a transformação da administração urbana no capitalismo tardio. Geografiska Annaler, volume 71, 1989. Disponível em:

<https://edisciplinas.usp.br/pluginfile.php/2078 563/mod_resource/content/1/Harvey_Do\%20ger enciamento $\% 20 \mathrm{ao} \% 20$ empresariamento $\% 20 \% 2$ 81\%29.pdf>.

KING. A.D. Cidades pós-coloniais. Universidade Estadual de Nova York Binghamton, Binghamton, NY, EUA. 2009.

KING, Anthony D. What's happening to world city research? International Network for Urban Research and Action, Suíça. 2007. Disponível em: <http://www.scielo.br/scielo.php?script=sci_artte xt\&pid=S0103-21862010000200002>.
LEAL, Suely. Fetiche da Participação Popular: novas práticas de planejamento, gestão e governança democrática no Recife - Brasil. Recife, Editora CEPE, 2003.

LEAL, Suely. As veias abertas do planejamento urbano e a avalanche da governança do mercado. Desenvolvimento, planejamento e gestão, Editora UFPE, 2014. Disponível em:

<http://www.anpur.org.br/publicacao/arquivos/ desenvolvimento-planejamento-e-

governanca.pdf $>$.

LEFEBVRE, Henri. O Direito à Cidade. São Paulo, Editora Centauro, 2001.

RECIFE. Plano Específico para a Zona Especial de Preservação do Patrimônio Histórico e Cultural ZEPH 19 Hospital de Santo Amaro/Vila Naval. Plano Específico Santo Amaro Norte, versão para discussão, 2017. Disponível em:

<http://conselhodacidade.recife.pe.gov.br/sites/d efault/files/biblioteca/Minuta\%20PL\%20$\% 20$ Plano\%20Espec\%C3\%ADfico $\% 20$ Santo $\% 20$ Amaro\%20Norte_0.pdf>.

ROY, Ananya. Cidades faveladas: Repensando o Urbanismo Subalterno. E-metropolis, edição n ${ }^{\circ} 31$, 2017. Disponível em:

<http://emetropolis.net/system/edicoes/arquivo _pdfs/000/000/031/original/emetropolis31.pdf? 1513867097>.

SANTOS, Milton. Técnica, Espaço, Tempo:

Globalização e meio técnico-científico informacional. São Paulo: Editora da Universidade de São Paulo, 2008. 